\title{
Localized extinction of an arboreal desert lizard caused by habitat fragmentation
}

\author{
Adrian Munguia-Vega ${ }^{\mathrm{a}, \Uparrow}$, Ricardo Rodriguez-Estrella ${ }^{\mathrm{b}, \mathrm{c}}$, William W. Shaw ${ }^{\mathrm{d}}$, Melanie Culver ${ }^{\text {a }}$ \\ ${ }^{\text {a }}$ Conservation Genetics Laboratory, Arizona Cooperative Fish and Wildlife Research Unit, USGS, School of Natural Resources and the Environment, University of Arizona, Tucson, \\ AZ 85721, USA \\ ${ }^{\mathrm{b}}$ Centro de Investigaciones Biológicas del Noroeste, S.C. Mar Bermejo 195, Playa Palo Santa Rita, La Paz, Baja California Sur 23090, Mexico \\ ${ }^{c}$ Estación Biológica de Doñana, CSIC, Av. Americo Vespucio s/n, Sevilla 41092, Spain \\ ${ }^{\mathrm{d}}$ School of Natural Resources and the Environment, University of Arizona, Tucson, AZ 85721, USA
}

\section{Keywords:}

Ectotherm

Reptile

Extinction

Overheating

Global warming

Microsatellites

\begin{abstract}
a b s t r a c t
We adopted a species' perspective for predicting extinction risk in a small, endemic, and strictly scansorial lizard (Urosaurus nigricaudus), in an old ( $~ 60$ year) and highly fragmented (8\% habitat remaining) agricultural landscape from the Sonoran Desert, Mexico. We genotyped 10 microsatellite loci in 280 individuals from 11 populations in fragmented and continuous habitat. Individual dispersal was restricted to less than $400 \mathrm{~m}$, according to analyses of spatial autocorrelation and spatially explicit Bayesian assignment methods. Within this scale, continuous areas and narrow washes with native vegetation allowed high levels of gene flow over tens of kilometers. In the absence of the native vegetation, cleared areas and highways were identified as partial barriers. In contrast, outside the scale of dispersal, cleared areas behaved as complete barriers, and surveys corroborated the species went extinct after a few decades in all small (less than $45 \mathrm{ha}$ ), isolated habitat fragments. No evidence for significant loss of genetic diversity was found, but results suggested fragmentation increased the spatial scale of movements, relatedness, genetic structure, and potentially affected sex-biased dispersal. A plausible threshold of individual dispersal predicted only $23 \%$ of all fragments in the landscape were linked with migration from continuous habitat, while complete barriers isolated the majority of fragments. Our study suggested limited dispersal, coupled with an inability to use a homogeneous and hostile matrix without vegetation and shade, could result in frequent time-delayed extinctions of small ectotherms in highly fragmented desert landscapes, particularly considering an increase in the risk of overheating and a decrease in dispersal potential induced by global warming.
\end{abstract}

\section{Introduction}

The conversion of natural ecosystems into farmlands, mines and urban areas, driven by increasing population growth and food demand, along with climate change, are hallmarks of the human impacts on biodiversity in the 21st century (Pereira et al., 2010). Ectotherms, such as reptiles, have a high dependency to environmental conditions, and many species are at high risk of extinction by alterations to thermal niches induced by global warming (Sinervo et al., 2010). This is a concern particularly in warmer ecosystems like deserts, where reptiles show high diversity, abundance, and endemism (e.g., Grismer, 2002; Pianka, 1986), and where avoiding overheating is the main thermal challenge (Kearney et al., 2009). The loss and fragmentation of habitat could act in synergy with global warming increasing vulnerability to

$\Uparrow$ Corresponding author. Address: School of Natural Resources and the Environment, 1311 E. 4th Street, University of Arizona, Tucson, AZ 85721, USA. Tel.: +1 520 626 1636; fax: +1 5206218801 .

E-mail address: airdrian@email.arizona.edu (A. Munguia-Vega). extinction. Although it has been suggested that fragmentation of habitat could limit the capacity of populations to shift distributions on a large scale (Brook et al., 2008), impacts at the local scale remain poorly understood. For instance, the loss of vegetation cover by fragmentation could limit access to shade, further increasing thermal stress and the risk of local extinction by limiting activity time (Clusella-Trullas and Chown, 2011; Kearney et al., 2009). Even when arid regions in North America will experience the largest impacts of global warming (Seager and Vecchi, 2010; Weiss and Overpeck, 2005), few studies have documented the effects of habitat fragmentation on reptiles from desert habitats (Debinski and Holt, 2000; Ewers and Didham, 2006; McGarigal and Cushman, 2002; Storfer et al., 2010).

It is increasingly recognized that the spatial scale of dispersal, the dispersal behavior, and the habitat requirements for gene flow are characteristic of each species (Anderson et al., 2010; Ewers and Didham, 2006; Fischer and Lindenmayer, 2007). These interact with particular landscape attributes such as spatial arrangement, proportion of habitat remaining (With and King, 1999), and matrix quality, where distinct landscape features might show different 
degrees of permeability (partial and complete barriers, Landguth et al., 2010) to individual movements. At the end of the spatial continuum, some animal groups can show individual dispersal restricted to very small scales (few hundreds of meters), including ectotherms as lizards (Berry et al., 2005; Hoehn et al., 2007; Massot, 2003) and flightless invertebrates (Thiele, 1977), and endotherms such as rodents (Jones, 1993). Hence, they are predicted to be unable to move among even relatively close habitat fragments and go extinct first (Ewers and Didham, 2006; Fischer and Lindenmayer, 2007; Hoehn et al., 2007). Species dependent upon vital habitat resources absent from the matrix, such as native vegetation, could show reduced persistence compared to species that can live and disperse in the matrix (Ewers and Didham, 2006; Fischer and Lindenmayer, 2007; Vetter et al., 2011). For instance, the small (60-80 $\mathrm{mm}$ snout-vent length) threatened lizard Liolaemus lutzae, restricted to fragmented beach vegetation of the Atlantic Rainforest biome in Brazil show signs of population declines and has been eradicated from some heavily fragmented areas (Rocha et al., 2009). When limited dispersal combines with an inability to use the matrix, declining populations may superficially resemble a metapopulation in structure, but not function like one if they are not linked by migration and colonization (Driscoll et al., 2010; With, 2004). In addition, habitat fragmentation often is associated with loss of genetic variation, increase in genetic differentiation and inbreeding that also affect population viability (Frankham et al., 2002). Other endogenous density-dependent risks are associated with altered social interactions, including changes in territoriality, group size, and mating systems that have fitness consequences for individuals (Banks et al., 2007; Fischer and Lindenmayer, 2007). Identifying true (i.e., evolving and dynamic) metapopulations vs. time-delayed extinctions or extinction debt (Tilman et al., 1994), and developing creative solutions that ameliorate future impacts to biodiversity is a major pending challenge.

Here, we evaluated levels of genetic variation and structure at microsatellite loci in the black-tailed brush lizard, Urosaurus nigricaudus, from fragmented and continuous habitat in a old ( 60 year) agricultural valley from the Sonoran Desert in the Baja California Peninsula, Mexico, where the species has been excluded from the matrix. U. nigricaudus is a small (maximum $50 \mathrm{~mm}$ snoutvent length) heliotherm phrynosomatid lizard endemic to the Baja California Peninsula (Grismer, 2002). It is a common species, and although found in a wide variety of habitats throughout its range, is frequently climbing trees including Mesquite Prosopis palmeri, Palo Verde Cercidium floridum, several cacti, or boulders, where it eats a variety of small arthropods (Grismer, 2002). As in other related species of Urosaurus (Germaine and Wakeling, 2001; M'Closkey et al., 1987), during breeding season (April-August) U. nigricaudus males defend territories for potential mates, and the species is common within urban areas. It is considered threatened in Mexico (SEMARNAT, 2010), and least concern by the IUCN (Hollingsworth and Hammerson, 2007).

We predicted U. nigricaudus could be at high risk of local extinction in a fragmented landscape based on a limited dispersal potential observed in other lizards, its small size, which in ectotherms could accentuate overheating risk (Spotila et al., 1991), and its strictly scansorial behavior. Features in the matrix without vegetation that provides shade and refuge, such as those cleared for agriculture and paved highways, could have a negative effect on gene flow (partial barriers), while washes and urban areas could potentially allow individual dispersal. As the spatial and temporal scale of barriers increase, we expected to observe complete barriers characterized by a lack of gene flow, elevated genetic differentiation and relatedness, changes in dispersal behavior, and increased probability of extinction among isolated habitat fragments. We discuss the implications of our findings on the risk of local extinction at the landscape scale and in the face of global warming.

\section{Materials and methods}

\subsection{Study area}

The Santo Domingo valley represents the largest agricultural area in southern Baja California. This mensurative experiment (McGarigal and Cushman, 2002) was inadvertently initiated during the 1930s-1940s (Barret, 1974) in the Magdalena plain (Average precipitation $164 \mathrm{~mm}$ ). We estimated patterns of fragmentation from a series of aerial photographs taken in 1973, 1993 originally taken by INEGI (www.inegi.org.mx), and recent (Landsat 2008) satellite images. Files were exported to ARCMAP 10.0 (ESRI) where the images were ortho-rectified and the distinct landscape features digitized and geo-referenced as vectors. Today the fragmented landscape comprises $\sim 120,000$ ha of which only $8 \%$ remains native Sonoran Desert vegetation (Fig. 1). This native habitat is distributed among 122 habitat fragments isolated by areas where all the native vegetation has been cleared for agriculture (Fig. 1). Most of the cleared areas are currently unused ( $80 \%)$ due to salinization problems caused by over exploitation of the aquifer (Cardona et al., 2004). The trans-peninsular highway was completed with two lanes in 1961 (Barret, 1974) and the section between the cities of Insurgentes and Constitucion expanded to four lanes in 2004. One major wash (Bramonas, Fig. 1) has an east-west seasonal discharge and supports a continuous strip ( $100-1000$ m wide) of native vegetation (including Mesquite and Palo Verde) across $\sim 30 \mathrm{~km}$ of cleared areas. The statistics related to size and connectivity of the fragments were calculated using the GIS extension Patch Analyst 3.3 (Elkie et al., 1999). Minimum straight edge-to-edge Euclidean distances separating habitat fragments from the closest fragment or continuous area and minimum path distances connecting continuous areas were estimated using ARCMAP. Isolation was measured based on the amount of habitat within a $1 \mathrm{~km}$ buffer distance from the edge of the fragment.

\subsection{Sampling}

During June-July of 2007-2009, we surveyed ten habitat fragments with four $500 \mathrm{~m}$ transects within each fragment during two consecutive years. We recorded individual GPS coordinates and preserved in $70 \%$ ethanol $\sim 3 \mathrm{~mm}$ of the tail tip of each individual for genetic analyses. We also collected samples from four areas of continuous Sonoran Desert habitat surrounding the fragmented landscape (labeled NW, NE, SW and SE in Fig. 1) that were used as controls to infer the effects of habitat fragmentation. We also sampled two nearby populations (WW, WE) located along Las Bramonas wash and separated only by a four-lane highway.

\subsection{Genotyping}

Genomic DNA was extracted using DNeasy blood and tissue kits (Qiagen). All samples were genotyped at 10 polymorphic microsatellite DNA loci, including seven loci reported previously (Rodriguez-Estrella et al., 2006), and three additional loci described here (Table 2). Polymerase chain reactions (PCRs) were performed as previously described (Rodriguez-Estrella et al., 2006) except the universal M13 primer was added to the $5^{0}$ end of the forward primers to allow fluorescent labeling (Schuelke, 2000). Microsatellite genotyping was performed on an ABI PRISM 3730XL Genetic Analyzer (Applied Biosystems). Allele sizes were estimated using GENOTYPER 3.7 (Applied Biosystems) and classified into bins using FLEXIBIN (Amos et al., 2007). 


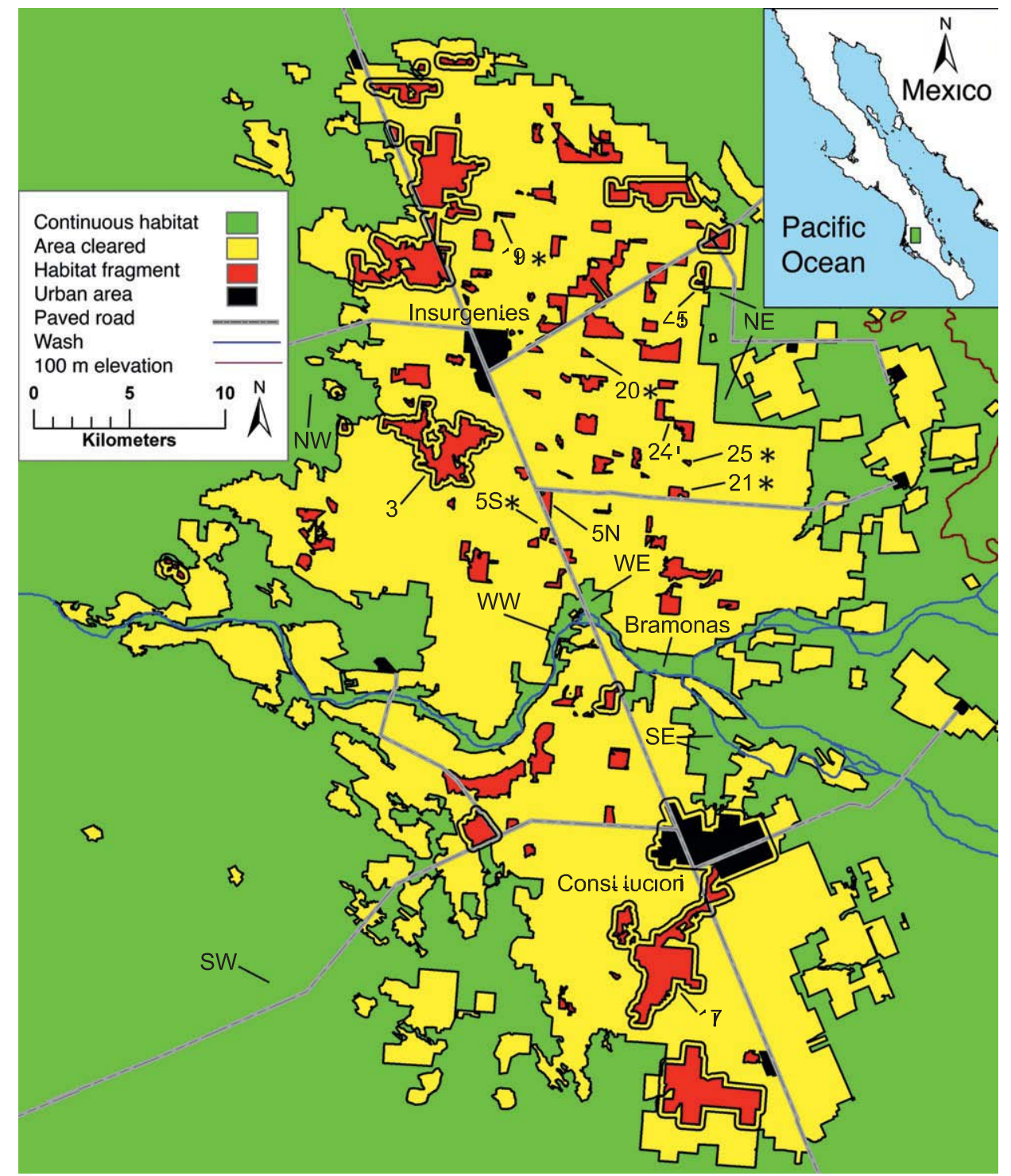

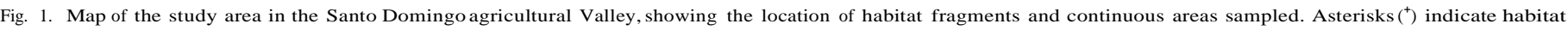

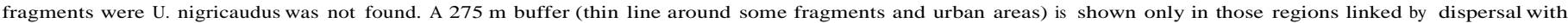
continuous habitat and with low probability of extinction, based on the scale of individual dispersal inferred in our analyses.

\subsection{Statistical analyses}

Deviations from Hardy-Weinberg equilibrium per locus and population, and linkage equilibrium among pairs of loci were estimated using FSTAT 2.9.3.2 (Goudet, 1995). Adjusted P values were obtained using a sequential Bonferronitest for multiple comparisons at $\mathrm{a}=0.05$. We calculated observed and expected heterozygosities and number of alleles using GENALEX 6.4 (Peakall and Smouse, 2006), as well as Fst and relatedness (Queller and Goodnight, 1989) employing FSTAT. Significance in genotypic differentiation was obtained employing a log-likelihood based exact test as implemented in GENEPOP 4.0.1 (Raymond and Rousset, 1995). We also calculated Gst' (Hedrick, 2005) and the actual differentiation D (Jost, 2008) using the software GENODIVE 2.0b20 (Meirmans and Van Tienderen, 2004).

We estimated the spatial scale of genetic structure with a spatial autocorrelation analysis implemented in GENALEX. Analyses were performed for all samples simultaneously $(\mathrm{N}=280)$ and using various data partitions and its possible combinations including: males, females, and continuous and fragmented habitat. This method used pairwise geographical and squared individual- by-individual $(\mathrm{N} \times \mathrm{N})$ genetic distance matrices for co-dominant data (Smouse and Peakall, 1999), to generate a coefficient (r) among individuals within 10 even-distance bins (50 m each). Statistical significance was achieved with 1000 permutations and 1000 bootstraps to estimate $95 \%$ confidence intervals. The method has high power for detecting genetic structure and sex-biased dispersal particularly over small spatial scales (Banks and Peakall, 2012; Epperson, 2010).

To test our hypotheses concerning the effect of distinct landscape features on dispersal, we contrasted pairs of sampled sites separated by increasing linear (minimum path) distances within continuous habitat (including sites along a main wash) with those separated by a single barrier (i.e., cleared areas covering increasing distances, paved highway and urban areas) an approach with high power to detect landscape effects on dispersal (Jaquiery et al., 2011). For all potential population pairs in the fragmented landscape, we focused on inferring migration between each habitat fragment and its three closest populations sampled.

We employed the Bayesian clustering methods implemented in STRUCTURE 2.3.1 (Hubisz et al., 2009; Pritchard et al., 2000) and GENELAND (Guillot et al., 2005) to test for the absence or presence 
Table 1

Characteristics of the 10 habitat fragments surveyed: name, area, edge, connectivity measured as the amount of habitat $(\mathrm{H})$ within a buffer distance of $1000 \mathrm{~m}$ from the patch's edge, minimum straight edge-to-edge distance separating the fragment from the nearest fragment (DNF), or to the nearest continuous habitat (DNC) and age for the estimated time since isolation (I)

\begin{tabular}{lllrrrr}
\hline $\begin{array}{l}\text { Habitat } \\
\text { fragment }\end{array}$ & $\begin{array}{l}\text { Area } \\
\text { (ha) }\end{array}$ & $\begin{array}{l}\text { Edge } \\
(\mathrm{m})\end{array}$ & H (ha) & \multicolumn{1}{c}{$\begin{array}{l}\text { DNF } \\
(\mathrm{m})\end{array}$} & \multicolumn{1}{l}{$\begin{array}{l}\text { DNC } \\
(\mathrm{m})\end{array}$} & I (y) \\
\hline 17 & 954.46 & 33643 & 3.17 & 38 & 753 & 4 \\
3 & 641.18 & 33472 & 124.53 & 445 & 175 & $35-60$ \\
24 & 116.90 & 10133 & 28.74 & 630 & 1075 & $15-35$ \\
$5 \mathrm{~N}$ & 59.56 & 4945 & 26.47 & 358 & 3650 & $35-60$ \\
$21^{\mathrm{a}}$ & 45.03 & 3419 & 0 & 1190 & 3805 & $15-35$ \\
$5 \mathrm{~S}^{\mathrm{a}}$ & 17.71 & 1985 & 39.07 & 358 & 3535 & $35-60$ \\
$19^{\mathrm{a}}$ & 12.70 & 2209 & 23.61 & 644 & 3966 & $15-35$ \\
$20^{\mathrm{a}}$ & 11.74 & 1704 & 20.40 & 637 & 5487 & $15-35$ \\
45 & 7.02 & 1480 & 54.13 & 98 & 113 & $15-35$ \\
$25^{\mathrm{a}}$ & 6.07 & 1278 & 0 & 1015 & 2390 & $15-35$ \\
\hline
\end{tabular}

${ }^{\text {a }}$ Habitat fragments where U. nigricaudus was not found.

of a barrier to dispersal between population pairs. In STRUCTURE, we used a categorical variable for defining sampling location to modify the prior distribution for each individual's population assignment, since it allows for structure to be detected at low levels of divergence (Hubisz et al., 2009). In contrast, GENELAND used the actual GPS coordinates. For every pair of populations, five independent STRUCTURE runs assuming one $(\mathrm{K}=1)$ and two $(\mathrm{K}=2)$ predefined populations or clusters were performed using a burnin period of 250,000 Markov chain Monte Carlo (MCMC) repetitions followed by 250,000 repetitions to sample from the posterior distribution. We did not implement the commonly used DK method for estimating the number of clusters, because it cannot find the best $\mathrm{K}$ if the true $\mathrm{K}=1$ (Evanno et al., 2005). Instead, we use an ad hoc method and compared the average of the probability for the presence of $K=1$ and $K=2$ given the data (Eq. (12) in Pritchard et al., 2000), and selected the larger value as the most likely estimate. Admixture and correlated allele frequencies were assumed as recommended for cases of low differentiation (Falush et al., 2003) and also because admixture models are more robust even if populations are diverging. Since independent runs may obtain similar membership coefficient estimates, but with a different cluster label (i.e., "label switching"'), we used a full search in CLUMPP 1.1 (Jakobsson and Rosenberg, 2007), and the output was entered into DISTRUCT 1.1 for display (Rosenberg, 2004). Individuals with an assignment probability $<50 \%$ to the population where they were sampled were considered misassigned and with a predominantly migrant ancestry. In GENELAND, five independent runs of 1 million iterations, sampling every 1000th, with $\mathrm{K}$ from 1 to 5 were used, in order to explore the possibility of noise introduced by potential intrademic structure (Anderson et al., 2010). We employed the spatial model with null alleles, a maximum of 300 nuclei, no uncertainty on coordinates, and correlated allele frequencies to improve the detection of subtle genetic structure (Guillot, 2008). We discarded the first $25 \%$ of the run as the burn-in period and sampled the posterior distribution of $\mathrm{K}$ values to estimate $\mathrm{K}$ mode. Additionally, for each population pair compared, we calculated Fst and the standardized Gst' resampling individuals and loci 1000 times (Neff and Fraser, 2010), and the actual differentiation $\mathrm{D}$.

We tested for changes in sex-biased dispersal driven by low population density within habitat fragments. Under male territoriality in continuous populations, a higher genetic similarity among males is expected compared to non-territorial females. We calculated relatedness values for males and females over all fragments and continuous habitats using FSTAT, and for each sex separately within each sampled population employing GENALEX. We conducted 1000 permutations to estimate significance levels.
Table 2

Characteristics of three microsatellite loci isolated from U. nigricaudus including: locus name, GenBank accession number, cloned repeat motif, primer sequences and size of cloned allele.

\begin{tabular}{|c|c|c|c|}
\hline Locus/GenBank & Motif & Primer sequences $\left(5^{0}-3^{0}\right)$ & $\begin{array}{l}\text { Clone size } \\
\text { (bp) }\end{array}$ \\
\hline Urni03 GU797085 & $(\text { TTCC })_{8}$ & $\begin{array}{l}\text { F: GTGCTAGTTGGCATTAGTGC } \\
\text { R: CCTTTCGCTTTTTTCATCAGCAG }\end{array}$ & 186 \\
\hline Urni66 GU797086 & $(\mathrm{CAA})_{4}$ & $\begin{array}{l}\text { F: CCACCTTGATTCCCATTATTGG } \\
\text { R: CAAGAACATTTGCACTCATCCC }\end{array}$ & 143 \\
\hline Urni82 GU797087 & $(\mathrm{CAA})_{7}$ & $\begin{array}{l}\text { F: GCATTATCCCAGTTTACTTCCTG } \\
\text { R: CTCGTGCCACTATCCAAACAC }\end{array}$ & 219 \\
\hline
\end{tabular}

Lastly, in order to explore the consequences of the spatial extent of dispersal on landscape connectivity, we defined complete barriers that prevented all migration and recolonization as cleared areas larger than $275 \mathrm{~m}$ from the edge of each habitat fragment. This threshold represents the observed intercept where patterns of spatial autocorrelation become zero within continuous areas, and is also consistent with multiple lines of evidence about the scale of dispersal in the species (see below). In ARCMAP, we constructed buffers of $275 \mathrm{~m}$ around each fragment and identified those whose buffers intersected continuous areas either directly or indirectly through links with other fragments under the same criteria. All other fragments were considered completely isolated and with high probability of local extinction. Based on our results, highways and urban areas were assumed to represent partial barriers.

\section{Results}

Our study documented the absence of U. nigricaudus in five out of the 10 fragments surveyed. Four of the fragments where the species was not found were only 15-35 years old, but all were typically small (645 ha) and located far from the nearest continuous area (P2390 m) (Table 1). Two-hundred and eighty individual lizards from 11 populations (five habitat fragments and six continuous areas) were captured and genotyped at 10 microsatellite loci. Combined, the 10 loci provided a negligible probability of identity $\left(1.37 \times 10^{-10}\right)$, and since each individual had a unique genotype, all were included in the final dataset. We found no evidence of significant deviations from Hardy-Weinberg equilibrium at a total of 110 tests (all adjusted $\mathrm{P}>0.0004$ ). From a total of 495 tests of departures from linkage equilibrium, we found only two instances of significant disequilibrium $(\mathrm{P}<0.0001$, loci Urni57 $\times$ Urni60 at fragment 44 and loci Urni56 $\times$ Urni69 at fragment 3). All loci were therefore assumed to be independent in all subsequent analyses.

\subsection{Genetic diversity and structure}

Overall observed and expected heterozygosities at habitat fragments (Table 3, 0.637, 95\% CI \pm 0.055 ; $0.656 \pm 0.051$ respectively) were similar and not significantly different from continuous habitat $(0.596 \pm 0.052$, t-test: $P=0.184 ; 0.649 \pm 0.05$, t-test: $\mathrm{P}=0.811$, respectively). The number of alleles observed in habitat fragments $(6.74 \pm 0.97)$ were lower, as expected, but not significantly different from continuous habitat $(7.55 \pm 0.99$, t-test: $\mathrm{P}=0.282$ ). All the indices of genetic differentiation and relatedness within habitat fragments (Fst $=0.027 \pm 0.008$, Gst $=0.83, \mathrm{D}=0.05$, $\mathrm{R}=0.051 \pm 0.013$ ) were, as predicted, higher compared to continuous habitat, but differences were not significant (Fst $=0.023$ \pm 0.007 , t-test: $P=0.540, G s t=0.67, \quad D=0.043, R=0.040 \pm 0.012$, t-test: $\mathrm{P}=0.359)$. In the pairwise comparison among sampled populations, the two measures of genetic differentiation (Fst and D) produced rankings that were qualitatively similar (Fig. 2). The null 
Table 3

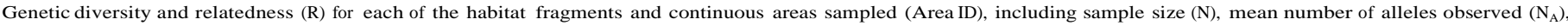

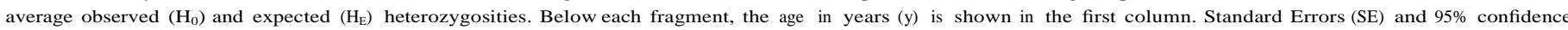
intervals (CI) are given in parenthesis.

\begin{tabular}{|c|c|c|c|c|c|}
\hline Area ID age (y) & $\mathrm{N}$ & $\mathrm{N}_{\mathrm{A}}( \pm \mathrm{SE})$ & $\mathrm{H}_{0}( \pm \mathrm{SE})$ & $\mathrm{H}_{\mathrm{E}}( \pm \mathrm{SE})$ & $\mathrm{R}(95 \% \mathrm{CI})$ \\
\hline Fragmented 3 (35-60) & 31 & $6.7( \pm 1.36)$ & $0.587( \pm 0.06)$ & $0.629( \pm 0.06)$ & $0.075(0.057,0.092)^{*}$ \\
\hline $5 \mathrm{~N}(35-60)$ & 26 & $6( \pm 0.86)$ & $0.612( \pm 0.06)$ & $0.640( \pm 0.05)$ & $0.060(0.036,0.086)^{*}$ \\
\hline $24(15-35)$ & 18 & $6.1( \pm 1.04)$ & $0.650( \pm 0.06)$ & $0.659( \pm 0.05)$ & $0.037(0.004,0.067$ \\
\hline 45 (15-35) & 19 & $7( \pm 1.14)$ & $0.700( \pm 0.06)$ & $0.668( \pm 0.05)$ & $0.008(-0.023,0.042)$ \\
\hline $17(4)$ & 25 & $7.5( \pm 1.22)$ & $0.636( \pm 0.06)$ & $0.669( \pm 0.06)$ & $-0.016(-0.036,0.005)$ \\
\hline Average & 23.8 & $6.74( \pm 0.49)$ & $0.637( \pm 0.02)$ & $0.656( \pm 0.02)$ & $0.051(0.038,0.064)$ \\
\hline \multicolumn{6}{|l|}{ Continuous } \\
\hline NW & 23 & $7.6( \pm 1.24)$ & $0.578( \pm 0.05)$ & $0.640( \pm 0.06)$ & $0.069(0.039,0.095)^{*}$ \\
\hline $\mathrm{NE}$ & 28 & $8.0( \pm 1.28)$ & $0.632( \pm 0.06)$ & $0.678( \pm 0.06)$ & $-0.018(-0.037,0.003)$ \\
\hline SW & 31 & $7.4( \pm 1.22)$ & $0.613( \pm 0.06)$ & $0.620( \pm 0.06)$ & $0.091(0.069,0.112)^{*}$ \\
\hline SE & 30 & $7.4( \pm 1.24)$ & $0.663( \pm 0.05)$ & $0.683( \pm 0.05)$ & $-0.020(-0.039,-0.001)$ \\
\hline \multicolumn{6}{|l|}{ Wash } \\
\hline WW & 26 & $7.9( \pm 1.54)$ & $0.577( \pm 0.09)$ & $0.641( \pm 0.07)$ & $0.062(0.042,0.083)^{*}$ \\
\hline WE & 23 & $7( \pm 1.19)$ & $0.513( \pm 0.06)$ & $0.633( \pm 0.07)$ & $0.034(0.013,0.057)$ \\
\hline Average & 26.8 & $7.55( \pm 0.50)$ & $0.596( \pm 0.02)$ & $0.649( \pm 0.02)$ & $0.040(0.028,0.052)$ \\
\hline
\end{tabular}

Indicates significant relatedness $\left({ }^{+} \mathrm{P}<0.05\right)$.

hypothesis of homogeneous genotype frequencies was rejected $(\mathrm{P}<0.001)$. Significant genotypic differentiation was detected among most fragmented populations, excepting one young fragment (24) located nearby from a continuous area. Except for population SW, Fst values between continuous areas were low to moderate and not significant. We also observed a significant positive correlation between age of the fragment and average relatedness $\left(r^{2}=0.892, P=0.015\right)$. Although there was evidence of significantly increased relatedness in old (35-60 year) but not in younger fragments, instances of significantly increased relatedness were also observed within continuous habitat (Table3).

\subsection{Spatial autocorrelation}

The analysis of spatial autocorrelation among all individuals revealed significant patterns of genetic structure $(\mathrm{P}<0.05)$ within distance classes up to $400 \mathrm{~m}$ (Fig. 3). We show results for analyses over a $500 \mathrm{~m}$ scale (Fig. 3), since patterns over larger distances (e.g.

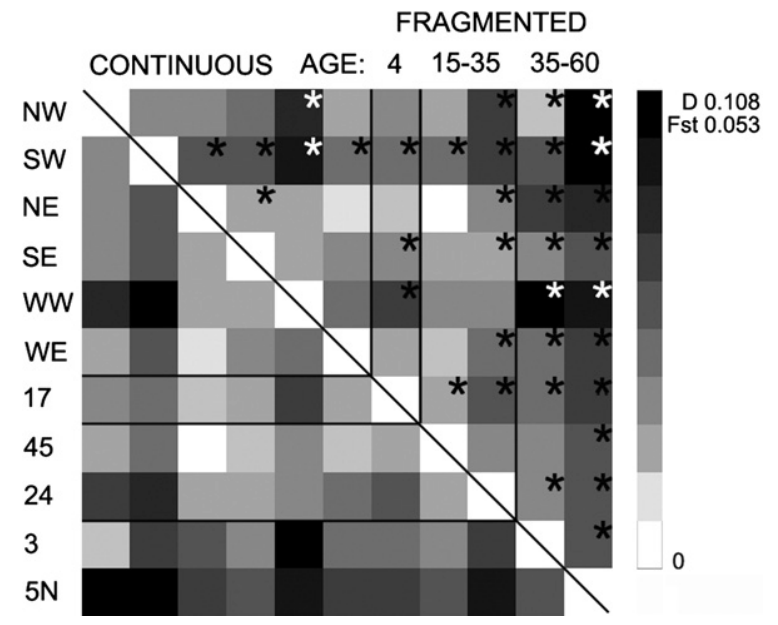

Fig. 2. Pairwise genetic differentiation (Fst, below) and true differentiation (D, above) among localities in continuous and fragmented habitat. For habitat fragments, age (in years) is shown in the horizontal labels. Vertical labels correspond to sampled localities as in Fig. 1. H Indicates significant genotypic differentiation according to an exact $\mathrm{G}$-test $(\mathrm{P}<0.0009)$.
0.5-2 km) were not significant. Within continuous habitat, individuals within $150 \mathrm{~m}$ had a significant positive correlation, while within fragments individuals displayed genetic structure up to $400 \mathrm{~m}$. Overall, males showed significant patterns over a larger scale $(200 \mathrm{~m})$ compared to females $(100 \mathrm{~m})$. In continuous habitat, males showed significant genetic structure only within $50 \mathrm{~m}$, while females had significant patterns over $150 \mathrm{~m}$, and both increased to $200 \mathrm{~m}$ in individuals sampled in fragmented habitat (Fig. 3).

\subsection{Bayesian assignment}

For brevity, here we show only some representative examples of the overall results. Results for all other pairwise comparisons conducted are available as online Appendix (Figs. A1 and A2, respectively). The number of clusters estimated with STRUCTURE was consistent with results from GENELAND for cases of low differentiation and high genetic differentiation, while at intermediate levels of structure GENELAND overestimated K (Fig. 4 and Table A1), a known issue of this software (Chen et al., 2007). In the analyses within the two continuous areas (NE and SE) where lizards were sampled at distances of 917 and $4837 \mathrm{~m}$, respectively (Fig. 4a), STRUCTURE assigned all individuals to the same cluster. In both cases, GENELAND showed $\mathrm{K}=1$ that were accompanied by low to moderate Gst values (0.078 and 0.118 , respectively), while Fst and D were zero. When two populations (SE vs. WE) separated by $12,274 \mathrm{~m}$ of continuous habitat along a wash were compared, we found a perfect assignment of SE, while for WE $13 \%$ of individuals were misassigned. GENELAND detected the presence of two moderately differentiated clusters (Fst $=0.019$, Gst $=0.099$, $\mathrm{D}=0.039$ ). Other populations within continuous areas, or connected along the wash showed evidence of high to moderate levels of recent migration over a $\sim 30 \mathrm{~km}$ scale while in the presence of a paved highway we observed comparatively higher levels of differentiation (Figs. 4a and A1). The average probability estimated from the data with STRUCTURE among all continuous populations consistently suggested a higher probability for $K=1$ compared to $\mathrm{K}=2$ (Table A1), supporting some level of gene flow.

Among the population pairs separated by potential barriers (Fig. 4b), we observed that two populations divided by $113 \mathrm{~m}$ of cleared area (45 vs. NE) were genetically indistinguishable from one another. STRUCTURE assigned all individuals to the same cluster and suggested $K=1$ (Table A1), GENELAND confirmed $K=1$, and 


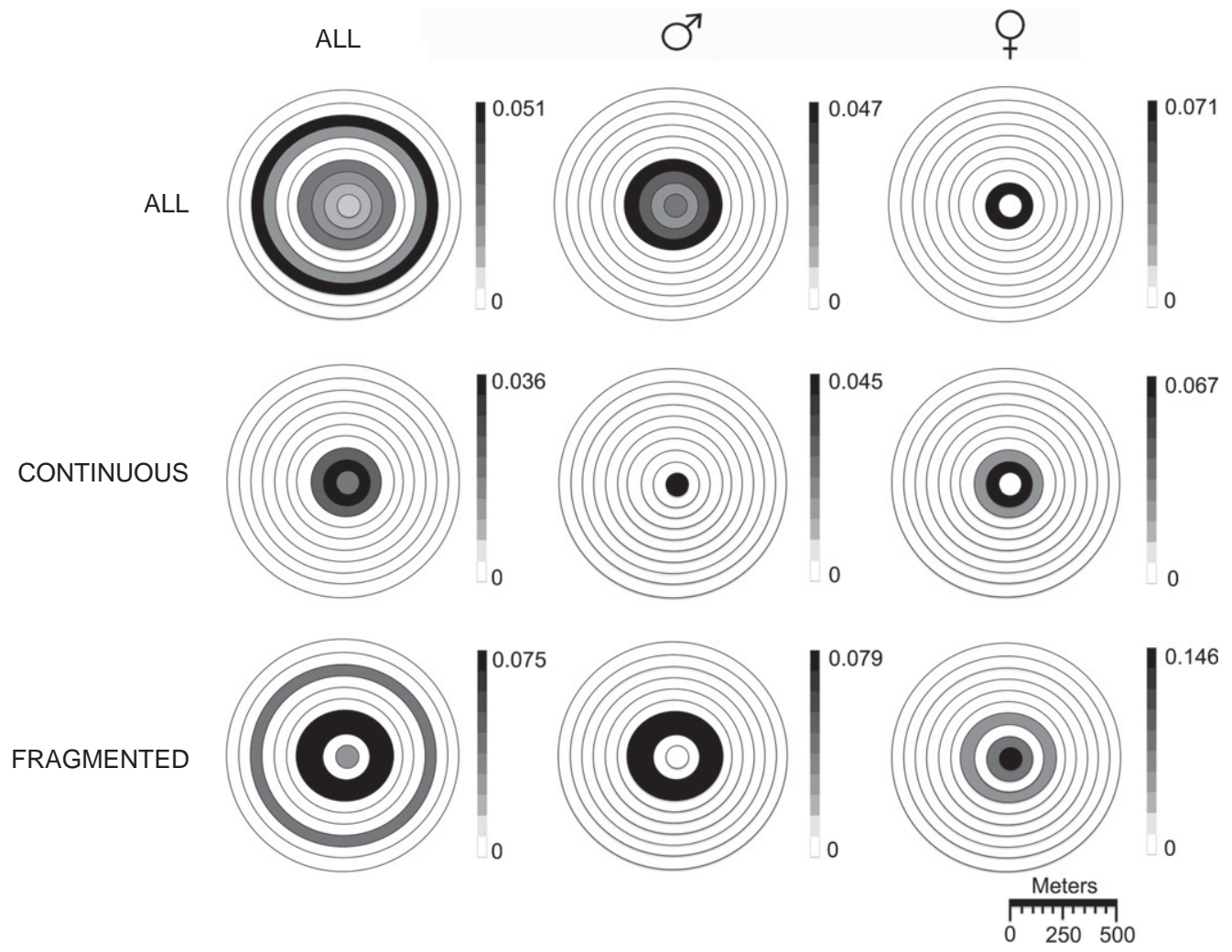

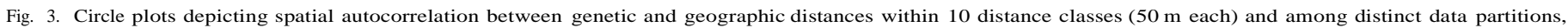

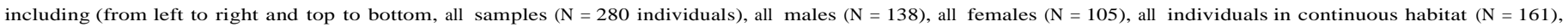

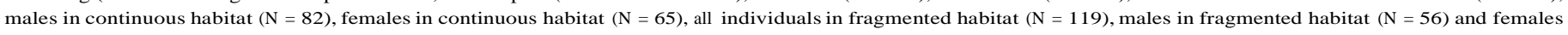

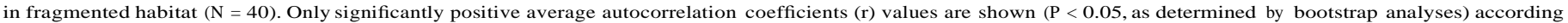
to the average maximum value observed within each analysis (indicated in the scale).

the level of differentiation estimated was very low (Gst $=0.057$, $\mathrm{D}=0.010$ ) or zero (Fst). As cleared areas increased to $175 \mathrm{~m}$ (3 vs. NW), we detected comparatively higher genetic differentiation (Fst $=0.010, \quad \mathrm{Gst}=0.073, \mathrm{D}=0.019$ ), but STRUCTURE suggested $\mathrm{K}=1$ indicating some gene flow (Table A1). When $\mathrm{K}=2$, it found five misassigned individuals (16\%) at fragment 3 , suggesting migration from the continuous area nearby, while GENELAND found $K=2$. When cleared areas increased to $1075 \mathrm{~m}$ (24 vs. NE) or more (e.g., $3625 \mathrm{~m}$ WE vs. 5, Figs. 4b and A2), we observed that STRUCTURE suggested $K=2$ (Table A1) and found a perfect assignment of each individual to the population where it was sampled suggesting complete barriers. In all these cases, GENELAND indicated the presence of two clusters that showed moderate to high genetic differentiation (range of averages: Fst $=0.016-0.053$, Gst $=0.113-0.168, \quad D=0.035-0.108)$. For the two populations (WW vs. WE) separated by the four-lane highway ( $\sim 30 \mathrm{~m}$ wide), STRUCTURE suggested $K=2$ (Table A1), and it showed an absence of misassigned individuals to the west of the barrier, and a high proportion of misassigned individuals (70\%) to the east. Comparatively, moderate levels of genetic differentiation were observed (Fst $=0.025$, Gst $=0.102, \mathrm{D}=0.048$ ), and GENELAND also found $\mathrm{K}=2$. A pair of populations separated by $\sim 2 \mathrm{~km}$ of urban areas showed low levels of structure (Fst $=0.015)$ and multiple individuals identified as migrants (Fig. A2).

\subsection{Sex-biased dispersal}

The sex ratio of the samples collected in continuous habitat areas and habitat fragments were similar and tended toward males, particularly among fragments $(55.7 \%$ and $58.3 \%)$, respectively, expressed as proportion of males). Relatedness among all males in continuous habitat $(\mathrm{R}=0.044,95 \%$ CI $0.028-0.061)$ was higher but not significantly different from the value estimated among females $(\mathrm{R}=0.037,0.010-0.071$, $\mathrm{t}$-test: $\mathrm{P}=0.720)$. Among habitat fragments, estimates within genders were identical to each other (males $\mathrm{R}=0.054,0.013-0.092$, females $\mathrm{R}=0.054,0.013-$ 0.091 ), and although in both cases relatedness increased compared to continuous habitat, the difference was not significant (t-test $\mathrm{P}=0.663$ and 0.549 for males and females, respectively). Within populations (Fig. 5), relatedness of males was consistently higher compared to females in continuous habitat, but this difference was significant only at population SE (males $\mathrm{R}=0.042,-0.008-$ 0.091 ; females $\mathrm{R}=-0.080,-0.108$ to -0.051 , t-test: $\mathrm{P}=0.001$ ). Within habitat fragments, we observed similar patterns at two fragments (5 and 45), but differences were not significant. In contrast, in the three largest habitat fragments (3, 24 and 17), we observed that females were more related compared to males. Of these, the difference was significant only at fragment 3 (males $\mathrm{R}=0.032, \quad 0.002-0.063$; females $\mathrm{R}=0.118,0.061-0.175$, t-test: $\mathrm{P}=0.006)$.

\subsection{Landscape connectivity}

A plausible threshold in the scale of dispersal for U. nigricaudus (smaller or equal to $275 \mathrm{~m}$ ) was overlaid around all habitat fragments $(\mathrm{N}=122)$. We found only $23 \%$ of all of them were likely connected through dispersal with continuous habitat (Fig. 1). These fragments accounted for $53 \%$ of the total remaining habitat, included the five largest fragments in the landscape, and were located exclusively around the interface of the fragmented matrix with surrounding continuous habitat. 


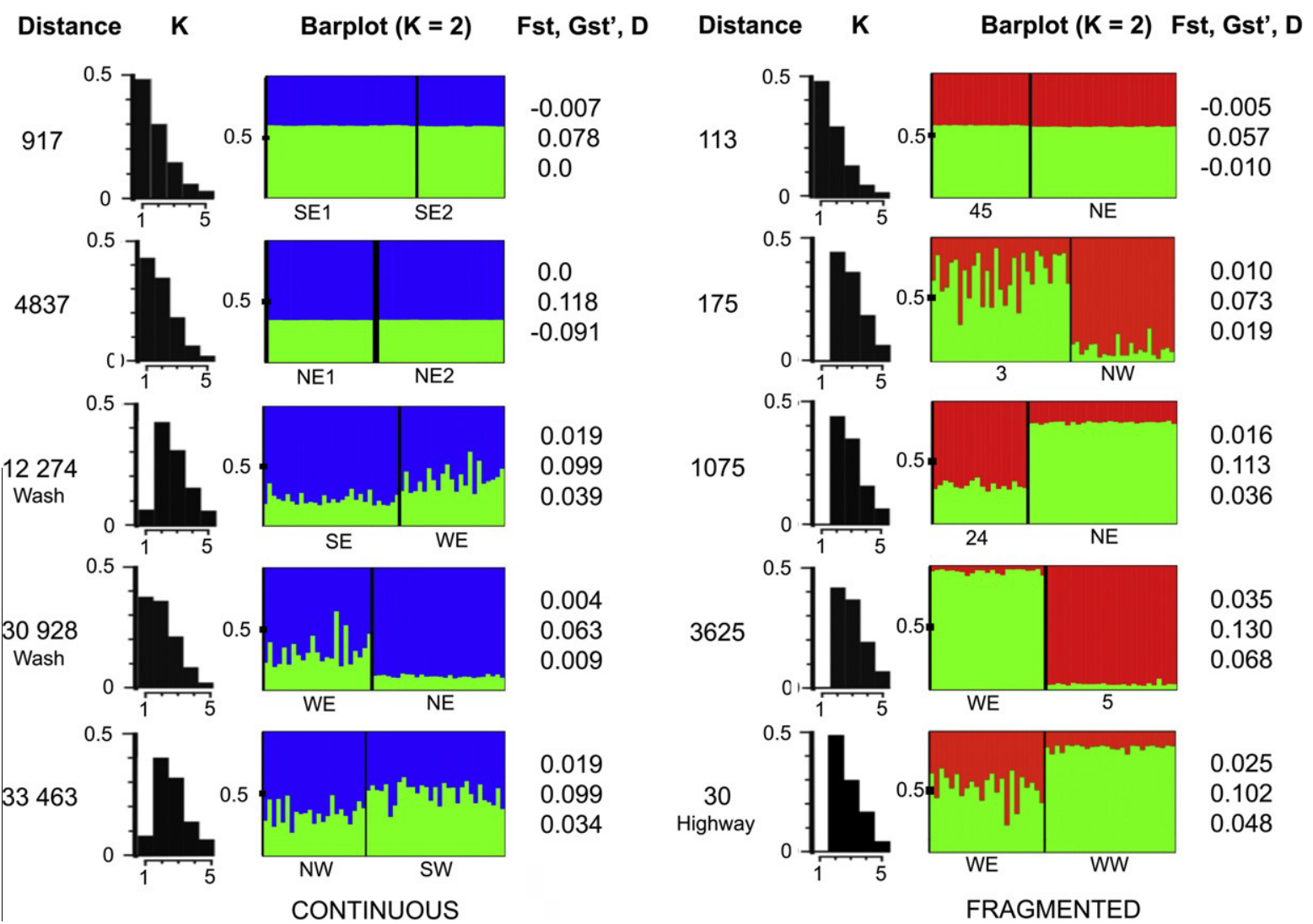

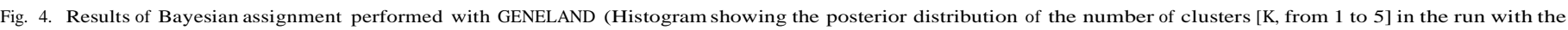

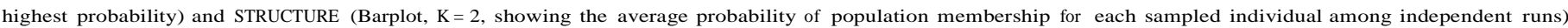

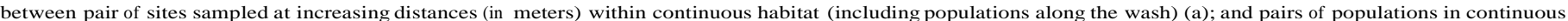

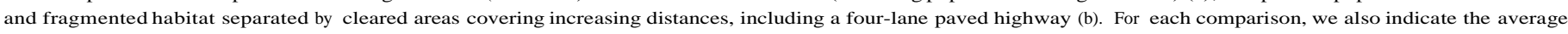
values for three indices of genetic differentiation (Fst, Gst' and D). The sites compared are indicated below each barplot and are shown in Fig. 1.

\section{Discussion}

Our study suggested the synergy between limited dispersal and an inability to use a fragmented and hostile matrix could result in frequent, spatially localized, time-delayed extinctions in a small ectotherm in a highly fragmented desert landscape. We found support for a small spatial scale of dispersal related to a small body size and scansorial behavior. Significant patterns of spatial autocorrelation were restricted to $150 \mathrm{~m}$ in continuous and $400 \mathrm{~m}$ in fragmented habitat, respectively. This result is similar to fragmented populations of two arboreal geckos where significant autocorrelation was found up to $200 \mathrm{~m}$ and $400 \mathrm{~m}$, respectively (Hoehn et al., 2007). Most spatial autocorrelation accumulates over 20-50 generations (Epperson, 2005) and typically overestimates Wright's

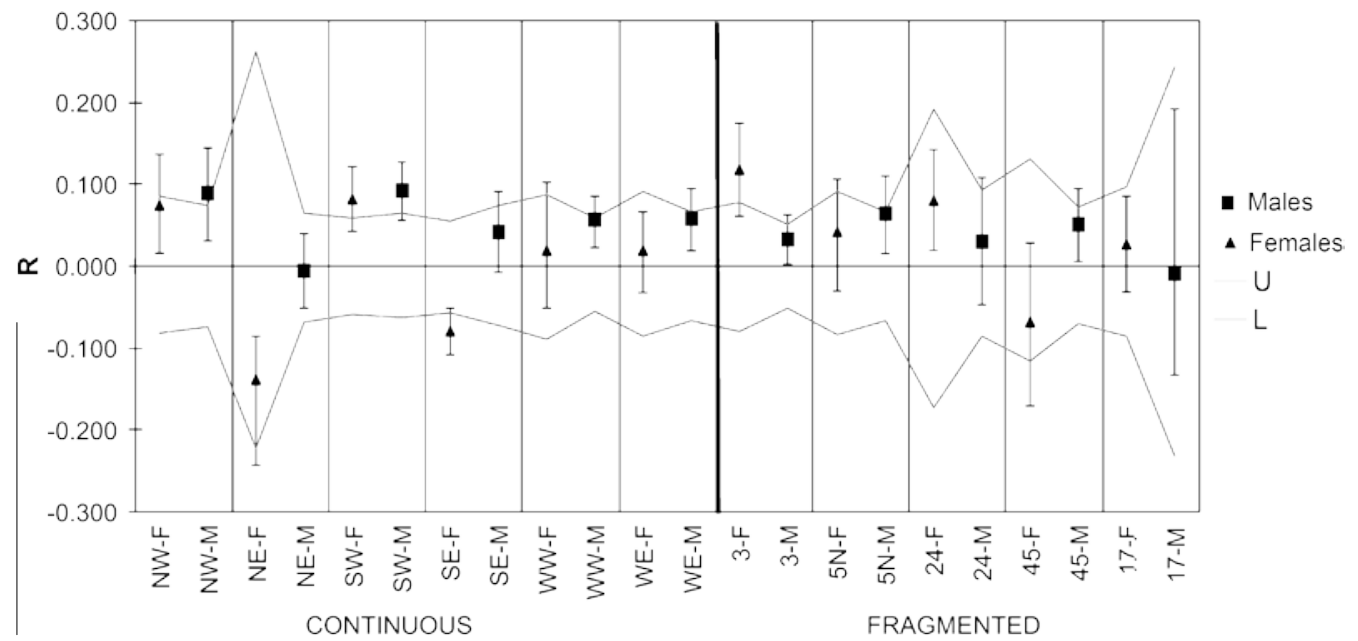

Fig. 5. Average relatedness (R) calculated within males and females at each of the six continuous areas and five habitat fragments sampled. Bars indicate $95 \%$ bootstrap

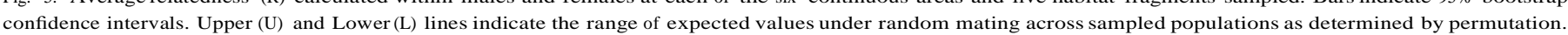


genetic neighborhoods describing parent-offspring dispersal distances (Anderson et al., 2010), suggesting individual dispersal in any given generation be even more restricted.

Levels of genetic variation in isolated populations were not significantly different from those observed in continuous habitat, suggesting sampled populations were remnants and not a result of extinction and recent recolonization. These patterns are consistent with other studies in lizards showing a slow loss of diversity even several decades after fragmentation (Delaney et al., 2010; Richmond et al., 2008) and could suggest relatively constant local effective sizes. However, patterns were consistent with a significant increase in relatedness within old fragments, and these also showed comparatively higher levels of differentiation than young fragments. Inbreeding and complete isolation, along with deterioration of the native vegetation community within habitat fragments (Stiles and Scheiner, 2010), could contribute to behavioral responses where individuals in fragmented habitat disperse larger distances and show stronger autocorrelation than in continuous habitat. In continuous habitat, males were consistently more related to each other than females and displayed genetic structure on a smaller spatial scale than females, a trend that is consistent with male territoriality under natural conditions. In the fragmented habitat, we observed that the spatial scale of structure increased to $200 \mathrm{~m}$ in both, suggesting fragmentation changed dispersal behavior more drastically in males, a pattern also supported within the three largest fragments where males were less related than females. Increased male dispersal in fragmented habitat could be a consequence of reduced access to females (M'Closkey et al., 1987) driven by low population density in large fragments after an initial "crowding" effect (Banks et al., 2007; Debinski and Holt, 2000; Ewers and Didham, 2006). Also, it could act as an inbreeding avoidance mechanism to counteract decreased female dispersal in habitat fragments (Stow et al., 2001) or result from male lizards embarking on dispersal attempts more frequently than females in the fragmented habitat (Levy et al., 2010). Mounting evidence suggest behavioral responses of lizards to fragmentation in the form of changes in sex-biased dispersal (Berry et al., 2005), particularly towards male-biased (Levy et al., 2010; Stow et al., 2001; Sumner, 2005). Increased dispersal as a response to fragmentation can increase the probability of spread of other perturbations acting in fragmented landscapes such as parasites and disease (Banks et al., 2007; Ewers and Didham, 2006), and intensify the risk of mortality associated with dispersal (Banks et al., 2007; Clutton-Brock and Lukas, 2011), contributing to low population densities, isolation and local extinction within fragments. However, our results did not support a drastic change in the sex ratio.

\subsection{Permeability of distinct landscape features}

We corroborated distinct landscape features have variable effects on dispersal. Despite limited dispersal, local populations of a relatively common species in continuous habitat were part of cohesive evolutionary units linked by migration over larger spatial and temporal scales, as corroborated by panmixia among populations separated by few to several kilometers. Within fragmented habitat, we observed that $-100 \mathrm{~m}$ of cleared areas does not represent any detectable barrier to gene flow. It is likely that gene flow over $\sim 100 \mathrm{~m}$ could be indeed reduced but still occur at a rate of one or more effective migrants per generation, completely counteracting the effect of genetic drift (Lacy, 1987). When the distance separating the pair of sampled populations increases to $175 \mathrm{~m}$, a partial barrier was inferred and few migrants detected that moved from the continuous area to the habitat fragment (but not vice versa). This directional pattern of migration as been observed previously, for instance, in an arboreal forest marsupial in remnants surrounded by plantations (Lancaster et al., 2011), and suggests that fragments act like sinks for migrant individuals from nearby continuous habitat. In contrast, all the pairwise comparisons between populations separated by cleared areas extending more than few hundred meters were consistent with the presence of complete barriers to dispersal (i.e., $\mathrm{K}=2$ ), suggesting high extinction risk on fragments isolated at this spatial scale. These results are also consistent with the exclusion of $U$. nigricaudus from the agricultural matrix.

Even when the extent of paved roads in terms of area and habitat quality in adjacent zones is small (Balkenhol and Waits, 2009), we were able to detect their impact as partial barriers to dispersal and population genetic structure wherever they were present. In addition to area effects, highways cause significant mortality for reptiles in deserts (Rosen and Lowe, 1994), while other studies have shown negative effects of roads on reptile abundance, diversity, and movement in other locations (Fahrig and Rytwinski, 2009). These patterns have been explained based on the fact that reptiles are attracted to roads (e.g., to help during thermoregulation in the morning) and on their relatively slow movements and consequently low car avoidance (Fahrig and Rytwinski, 2009). The combined effects of area and increased mortality seem to translate into increased barrier strength for highways compared to cleared areas over a similar spatial scale.

Our results showed that a wash (Bramonas, Fig. 1), which was the only feature that maintained habitat continuity across the entire fragmented landscape, consistently allowed gene flow among populations separated over few to tens of kilometers. This agrees with studies showing narrow (e.g., $100 \mathrm{~m}$ ) but continuous strips of vegetation (corridors) could favor the movement of some species and their genes across fragmented landscapes, as long as they provide suitable habitat (Debinski and Holt, 2000; Gilbert-Norton et al., 2010), and highlights the importance of washes as conservation targets to maintain landscape connectivity for small animals with limited dispersal potential in fragmented desert landscapes.

We found some support for the view that, as long as refuge and shade are present within the dispersal potential of the species, they could be replaced by functionally similar artificial structures that allow for retreat (e.g., buildings and exotic vegetation in urban areas) and dispersal. This is consistent with the observation that species of Urosaurus are common inhabitants of back-yards in high density urban areas from the Sonoran Desert, where their small size, scansorial behavior and limited dispersal seem to become key in their success to avoid mortality, compared to other lizards excluded from these areas (Germaine and Wakeling, 2001). These observations also highlight how ectotherms with limited dispersal can show contrasting risks of extinction depending on the spatial scales of fragmentation and the nature of the matrix.

\subsection{Conservation implications}

We identified a high risk of extinction for many isolated U. nigricaudus populations in a fragmented agricultural landscape from the Sonoran Desert. A high vulnerability of this small ectotherm is result of a combination of habitat loss and fragmentation, species-specific characteristics and the synergy with global warming. In our fragmented landscape, only a small proportion of habitat remains (8\%), and fragments are relatively isolated (average distance between fragments $3.2 \mathrm{~km}$, Fig. 1). Given a high contrast between habitat and matrix in deserts, migration and colonization success could heavily depend on the spatial scale of dispersal (Ovaskainen and Hanski, 2004). In an hostile matrix, individual dispersal was restricted to few hundred meters, and in line with island biogeography theory (MacArthur and Wilson, 1967), our surveys suggested U. nigricaudus populations in small $(<45 \mathrm{ha})$ isolated fragments could have become extinct, in most cases after only 15-35 year 
since isolation, in the absence of a rescue effect (Brown and KodricBrown, 1977). Our analyses using a plausible threshold of $275 \mathrm{~m}$ in the matrix representing complete barriers predicted $77 \%$ of the fragments in the entire landscape (representing half of the habitat remaining) are effectively isolated from continuous habitat, while only $23 \%$ of the fragments are likely linked by migration with continuous habitat. This suggests a large and previously unrecognized extinction debt, with delayed extinctions after several decades in large fragments, supporting some common small ectotherms can deviate from classic source-sink models in fragmented landscapes (Driscoll et al., 2010). It also highlights the risk of underestimating extinction vulnerability by relaying on the current distribution of a species in a fragmented landscape. Remarkably, true metapopulations were strictly localized in the vicinity of the interface of the matrix with continuous habitat. Nevertheless, this boundary, characterized by large fragments, recent fragmentation, and small distances between fragmented habitats, is often overlooked in many studies (but see Hargis et al., 1998; Lancaster et al., 2011). This interface contains populations with low risk of extinction, and where long-term conservation efforts for fragmented populations could be most fruitful and easer to implement, compared to the cost of restoring habitat connectivity to the scale needed (e.g., $50-200 \mathrm{~m}$ ) after its lost. The use of washes or similarly linear habitats as biological corridors seems particularly promising, and could help to link individual reserves, while isolated reserves would need to be large (e.g. larger than $50 \mathrm{ha}$ ) or supplemented with translocated individuals to prevent local extinction in the long-term.

The interaction among habitat destruction and the current alterations in the thermal niche of species due to global climatic changes (Sinervo et al., 2010) could cause an amplification of the overall risk of extinction, compared to the sum of the individual net effects (Brook et al., 2008). In this and other studies (Rocha et al., 2009), removal of vegetation cover by habitat loss and fragmentation limited the access to shade for a small lizard. In deserts, recovery of perennial vegetation is slow, even decades after disturbances ceased (Qinfeng, 2004). A low availability of shade as a result of habitat loss and fragmentation, along with global warming (Weiss and Overpeck, 2005), and small body size, limited dispersal potential and lack of burrowing behavior (as in U. nigricaudus), could translate into increased risk of overheating, unsustainably short activity times and large maintenance energy costs (Kearney et al., 2009; Sinervo et al., 2010), and a rapid loss of suitable niche space (Barrows et al., 2010). These suggest current estimates of the spatial scale of dispersal for ectotherms in fragmented habitats could underestimate the risk of extinction in the near future. For instance, some populations in fragmented landscapes that are currently connected by migrants from nearby areas of continuous habitat (e.g., Fig. 1) might become completely isolated if individual dispersal shrinks, even under the optimistic scenario that further habitat loss is completely halted. Habitat destruction and global warming increase the risk of local extinction for ectotherms, and understanding their individual and combined effects is a major challenge. Of particular concern are desert regions with numerous endemic species where local extinction could more easily translate into species extinction. This permanent loss of biodiversity can jeopardize ecosystems services (Cardinale et al., 2012).

\section{Acknowledgments}

We thank the Cota family (Abelino, Enrique, Franco) and specially Bruno Granados for their invaluable help trapping lizards. AMV was supported during the execution of this work by Consejo Nacional de Ciencia y Tecnologia (CONACyT; 158622), the Wallace Research Foundation and The David and Lucile Packard Foundation. This work was possible by projects funded by CONACYT-
SEMARNAT (2002-C01-0317) and CIBNOR S.C. to RRE, and by the following scholarships to AMV: William A. Calder III, William G. McGinnies, Rick F. Seegmiller (University of Arizona), Charles H. Lowe (Tucson Herpetological Society), Jiji Foundation. RRE received a sabbatical grant in the EBD, Spain, during the writing of this manuscript. We deeply thank Michael W. Nachman and three anonymous reviewers for improving the quality of this manuscript. Research protocol was approved by IACUC (09-119) and sampling was conducted under permit FAUT-0055.

\section{Appendix A. Supplementary material}

Supplementary data associated with this article can be found, in the online version, at http://dx.doi.org/10.1016/j.biocon.2012. 06.026.

\section{References}

Amos, W., Hoffman, J.I., Frodsham, A., Zhang, L., Best, S., Hill, A.V.S., 2007. Automated binning of microsatellite alleles: problems and solutions. Mol. Ecol. Notes 7, 10-14.

Anderson, C.D., Epperson, B.K., Fortin, M.J., Holderegger, R., James, P.M., Rosenberg, M.S., Scribner, K.T., Spear, S., 2010. Considering spatial and temporal scale in landscape-genetic studies of gene flow. Mol. Ecol. 19, 3565-3575.

Balkenhol, N., Waits, L.P., 2009. Molecular road ecology: exploring the potential of genetics for investigating transportation impacts on wildlife. Mol. Ecol. 18, 4151-4164.

Banks, S.C., Peakall, R., 2012. Genetic spatial autocorrelation can readily detect sexbiased dispersal. Mol. Ecol..

Banks, S.C., Piggott, M.P., Stow, A.J., Taylor, A.C., 2007. Sex and sociality in a disconnected world: a review of the impacts of habitat fragmentation on animal social interactions. Can. J. Zool. 85, 1065-1079.

Barret, E.M., 1974. Colonization of the Santo Domingo valley. Ann. Assoc. Am. Geogr. 64, 34-53.

Barrows, C.W., Rotenberry, J.T., Allen, M.F., 2010. Assessing sensitivity to climate change and drought variability of a sand dune endemic lizard. Biol. Conserv. 143, 731-736.

Berry, O., Tocher, M.D., Gleeson, D.M., Sarre, S.D., 2005. Effect of vegetation matrix on animal dispersal: genetic evidence from a study of endangered skinks. Conserv. Biol. 19, 855-864.

Brook, B.W., Sodhi, N.S., Bradshaw, C.J., 2008. Synergies among extinction drivers under global change. Trends Ecol. Evol. 23, 453-460.

Brown, J.H., Kodric-Brown, A., 1977. Turnover rates in insular biogeography: effect of immigration on extinction. Ecology 58, 445-449.

Cardinale, B.J., Duffy, J.E., Gonzalez, A., Hooper, D.U., Perrings, C., Venail, P., Narwani, A., Mace, G.M., Tilman, D., Wardle, D.A., Kinzig, A.P., Daily, G.C., Loreau, M., Grace, J.B., Larigauderie, A., Srivastava, D.S., Naeem, S., 2012. Biodiversity loss and its impact on humanity. Nature 486, 59-67.

Cardona, A., Carrillo-Rivera, J.J., Huizar-Alvarez, R., Graniel-Castro, E., 2004. Salinization in coastal aquifers of arid zones: an example from Santo Domingo, Baja California Sur, Mexico. Environ. Geol. 45, 350-366.

Chen, C., Durand, E., Forbes, F., Francois, O., 2007. Bayesian clustering algorithms ascertaining spatial population structure: a new computer program and a comparison study. Mol. Ecol. Notes 7, 747-756.

Clusella-Trullas, S., Chown, S.L., 2011. Comment on "Erosion of lizard diversity by climate change and altered thermal niches”, Science 332, 537.

Clutton-Brock, T.H., Lukas, D., 2011. The evolution of social philopatry and dispersal in female mammals. Mol. Ecol. 21, 472-492.

Debinski, D.M., Holt, R.D., 2000. A survey and overview of habitat fragmentation experiments. Conserv. Biol. 14, 342-355.

Delaney, K.S., Riley, S.P., Fisher, R.N., 2010. A rapid, strong, and convergent genetic response to urban habitat fragmentation in four divergent and widespread vertebrates. PloS One 5.

Driscoll, D.A., Kirkpatrick, J.B., McQuillan, P.B., Bonham, K.J., 2010. Classic metapopulations are rare among common beetle species from a naturally fragmented landscape. J. Anim. Ecol. 79, 294-303.

Elkie, P.C., Rempel, R.S., Carr, A.P., 1999. Patch Analyst User's Manual: A Tool for Quantifying Landscape Structure. Technical Manual TM-002. Ontario Ministry of Natural Resources, Ontario.

Epperson, B.K., 2005. Mutation at high rates reduces spatial structure within populations. Mol. Ecol. 14, 703-710.

Epperson, B.K., 2010. Spatial correlations at different spatial scales are themselves highly correlated in isolation by distance processes. Mol. Ecol. Resour. 10, 845853.

Evanno, G., Regnaut, S., Goudet, J., 2005. Detecting the number of clusters of individuals using the software STRUCTURE: a simulation study. Mol. Ecol. 14, 2611-2620.

Ewers, R.M., Didham, R.K., 2006. Confounding factors in the detection of species responses to habitat fragmentation. Biol. Rev. Camb. Philos. Soc. 81, 117-142.

Fahrig, L., Rytwinski, T., 2009. Effects of roads on animal abundance: an empirical review and synthesis. Ecol. Soc. 14, 21. 
Falush, D., Stephens, M., Pritchard, J.K., 2003. Inference of population structure using multilocus genotype data: linked loci and correlated allele frequencies. Genetics 164, 1567-1587.

Fischer, J., Lindenmayer, D.B., 2007. Landscape modification and habitat fragmentation: a synthesis. Glob. Ecol. Biogeogr. 16, 265-280.

Frankham, R., Ballou, J.D., Briscoe, D.A., 2002. Introduction to Conservation Genetics. Cambridge University Press, Cambridge.

Germaine, S.S., Wakeling, B.F., 2001. Lizard species distributions and habitat occupation along an urban gradient in Tucson, Arizona, USA. Biol. Conserv. 97, 229-237.

Gilbert-Norton, L., Wilson, R., Stevens, J.R., Beard, K.H., 2010. A meta-analytic review of corridor effectiveness. Conserv. Biol. 24, 660-668.

Goudet, J., 1995. FSTAT (Version 1.2): a computer program to calculate F-statistics. J. Hered. 86, 485-486.

Grismer, L.L., 2002. Amphibians and Reptiles of Baja California. University of California Press, Berkeley.

Guillot, G., 2008. Inference of structure in subdivided populations at low levels of genetic differentiation. The correlated allele frequencies model revisited. Bioinformatics 24, 2222-2228.

Guillot, G., Estoup, A., Mortier, F., Cosson, J.F., 2005. A spatial statistical model for landscape genetics. Genetics 170, 1261-1280.

Hargis, C.D., Bissonette, J.A., David, J.L., 1998. The behavior of landscape metrics commonly used in the study of habitat fragmentation. Landscape Ecol. 13, 167186.

Hedrick, P.W., 2005. A standardized genetic differentiation measure. Evolution 59, 1633-1638.

Hoehn, M., Sarre, S.D., Henle, K., 2007. The tales of two geckos: does dispersal prevent extinction in recently fragmented populations? Mol. Ecol. 16, 32993312.

Hollingsworth, B., Hammerson, G.A., 2007. Urosaurus nigricaudus. In: IUCN 2011. IUCN Red List of Threatened Species. Version 2011.1.

Hubisz, M.J., Falush, D., Stephens, M., Pritchard, J.K., 2009. Inferring weak population structure with the assistance of sample group information. Mol.Ecol. Resour. 9, 1322-1332.

Jakobsson, M., Rosenberg, N.A., 2007. CLUMPP: a cluster matching and permutation program for dealing with label switching and multimodality in analysis of population structure. Bioinformatics 23, 1801-1806.

Jaquiery, J., Broquet, T., Hirzel, A.H., Yearsley, J., Perrin, N., 2011. Inferring landscape effects on dispersal from genetic distances: how far can we go? Mol. Ecol. 20, 692-705.

Jones, T., 1993. Social systems of heteromyid rodents. In: Genoways, H.H., Brown, J.H. (Eds.), Biology of the Heteromyidae. American Society of Mammalogists, Shippensburg, Pennsylvania, pp. 575-595.

Jost, L., 2008. Gst and its relatives do not measure differentiation. Mol. Ecol. 17, 4015-4026.

Kearney, M., Shine, R., Porter, W.P., 2009. The potential for behaviora thermoregulation to buffer "cold-blooded" animals against climate warming. Proc. Natl. Acad. Sci. USA 106, 3835-3840.

Lacy, R.C., 1987. Loss of genetic diversity from managed populations: interacting effects of drift, mutation, immigration, selection, and population subdivision. Conserv. Biol. 1, 143-158.

Lancaster, M.L., Taylor, A.C., Cooper, S.J., Carthew, S.M., 2011. Limited ecological connectivity of an arboreal marsupial across a forest/plantation landscape despite apparent resilience to fragmentation. Mol. Ecol..

Landguth, E.L., Cushman, S.A., Murphy, M.A., Luikart, G., 2010. Relationships between migration rates and landscape resistance assessed using individualbased simulations. Mol. Ecol. Resour. 10, 854-862.

Levy, E., Kennington, J.W., Tomkins, J.L., Lebas, N.R., 2010. Land clearing reduces gene flow in the granite outcrop-dwelling lizard, Ctenophorus ornatus. Mol. Ecol. 19, 4192-4203.

MacArthur, R.H., Wilson, E.O., 1967. The Theory of Island Biogeography. Princeton University Press, Princeton, NJ.

Massot, M., 2003. Genetic, prenatal, and postnatal correlates of dispersal in hatchling fence lizards (Sceloporus occidentalis). Behav. Ecol. 14, 650-655.

McGarigal, K., Cushman, S.A., 2002. Comparative evaluation of experimental approaches to the study of habitat fragmentation effects. Ecol. Appl. 12, 335345

M’Closkey, R.T., Baia, K.A., Russell, R.W., 1987. Defense of mates: a territory departure rule for male tree lizards following sex-ratio manipulation. Oecologia 73, 28-31.

Meirmans, P.G., Van Tienderen, P.H., 2004. Genotype and genodive: two programs for the analysis of genetic diversity of asexual organisms. Mol. Ecol. Notes 4, 792-794.

Neff, B.D., Fraser, B.A., 2010. A program to compare genetic differentiation statistics across loci using resampling of individuals and loci. Mol. Ecol. Resour. 10, 546550.

Ovaskainen, O., Hanski, I., 2004. Metapopulation dynamics in highly fragmented landscapes. In: Ecology, Genetics and Evolution of Metapopulations. Elsevier Academic Press, Amsterdam, pp. 73-103.
Peakall, R.O.D., Smouse, P.E., 2006. Genalex 6: genetic analysis in Excel. Population genetic software for teaching and research. Mol. Ecol. Notes 6, 288-295.

Pereira, H.M., Leadley, P.W., Proenca, V., Alkemade, R., Scharlemann, J.P., FernandezManjarres, J.F., Araujo, M.B., Balvanera, P., Biggs, R., Cheung, W.W., Chini, L., Cooper, H.D., Gilman, E.L., Guenette, S., Hurtt, G.C., Huntington, H.P., Mace, G.M., Oberdorff, T., Revenga, C., Rodrigues, P., Scholes, R.J., Sumaila, U.R., Walpole, M., 2010. Scenarios for global biodiversity in the 21st century. Science 330, 14961501.

Pianka, E.R., 1986. Ecology and Natural History of Desert Lizards: Analyses of the Ecological Niche and Community Structure. Princeton University Press, Princeton, NJ.

Pritchard, J.K., Stephens, M., Donnelly, P., 2000. Inference of population structure using multilocus genotype data. Genetics 155, 945-959.

Qinfeng, G., 2004. Slow recovery in desert perennial vegetation following prolonged human disturbance. J. Veg. Sci. 15, 757-762.

Queller, D.C., Goodnight, K.F., 1989. Estimating relatedness using genetic markers. Evolution 43, 258-275.

Raymond, M., Rousset, F., 1995. GENEPOP (Version 1.2): population genetics software for exact tests and ecumenicism. J. Hered. 86, 248-249.

Richmond, J.Q., Reid, D.T., Ashton, K.G., Zamudio, K.R., 2008. Delayed genetic effects of habitat fragmentation on the ecologically specialized Florida sand skink (Plestiodon reynoldsi). Conserv. Genet. 10, 1281-1297.

Rocha, C.F.D., Siqueira, C.C., Ariani, C.V., 2009. The endemic and threatened lizard Liolaemus lutzae (Squamata: Liolaemidae): current geographic distribution and areas of occurrence with estimated population densities. Zoologia 26, 454-460.

Rodriguez-Estrella, R., Blazquez, M.C., Vega, A.M., 2006. Characterization of seven polymorphic microsatellite loci in the Baja California endemic black-tailed brush lizard Urosaurus nigricaudus. Mol. Ecol. Notes 6, 465-467.

Rosen, P.C., Lowe, C.H., 1994. Highway mortality of snakes in the sonoran desert of southern Arizona. Biol. Conserv. 68, 143-148.

Rosenberg, N.A., 2004. Distruct: a program for the graphical display of population structure. Mol. Ecol. Notes 4, 137-138.

Schuelke, M., 2000. An economic method for the fluorescent labeling of PCR fragments. Nat. Biotechnol. 18, 233-234.

Seager, R., Vecchi, G.A., 2010. Greenhouse warming and the 21st century hydroclimate of southwestern North America. Proc. Natl. Acad. Sci. USA 107, $21277-21282$.

SEMARNAT, 2010. NORMA Oficial Mexicana NOM-059-SEMARNAT-2010. Diario Oficial, 78pp.

Sinervo, B., Mendez-de-la-Cruz, F., Miles, D.B., Heulin, B., Bastiaans, E., VillagranSanta Cruz, M., Lara-Resendiz, R., Martinez-Mendez, N., Calderon-Espinosa, M.L., Meza-Lazaro, R.N., Gadsden, H., Avila, L.J., Morando, M., De la Riva, I.J., Victoriano Sepulveda, P., Rocha, C.F., Ibarguengoytia, N., Aguilar Puntriano, C., Massot, M., Lepetz, V., Oksanen, T.A., Chapple, D.G., Bauer, A.M., Branch, W.R., Clobert, J., Sites Jr., J.W., 2010. Erosion of lizard diversity by climate change and altered thermal niches. Science 328, 894-899.

Smouse, P.E., Peakall, R., 1999. Spatial autocorrelation analysis of individual multiallele and multilocus genetic structure. Heredity 82, 561-573.

Spotila, J.R., O’Connor, M.P., Dodson, P., Paladino, F.V., 1991. Hot and cold running dinosaurs: body size, metabolism and migration. Mod. Geol.16, 203-227.

Stiles, A., Scheiner, S.M., 2010. A multi-scale analysis of fragmentation effects on remnant plant species richness in Phoenix, Arizona. J. Biogeogr. 37, 17211729.

Storfer, A., Murphy, M.A., Spear, S.F., Holderegger, R., Waits, L.P., 2010. Landscape genetics: where are we now? Mol.Ecol. 19, 3496-3514.

Stow, A.J., Sunnucks, P., Briscoe, D.A., Gardner, M.G., 2001. The impact of habitat fragmentation on dispersal of Cunningham's skink (Egernia cunninghami): evidence from allelic and genotypic analyses of microsatellites. Mol. Ecol. 10, $867-878$.

Sumner, J., 2005. Decreased relatedness between male prickly forest skinks (Gnypetoscincus queenslandiae) in habitat fragments. Conserv. Genet. 6, 333340.

Thiele, H.U., 1977. Carabid Beetles in Their Environment: A Study on Habitat Selection by Adaptations in Physiology and Behavior. Springer, Berlin, Heidelberg, New York.

Tilman, D., May, R.M., Lehman, C.L., Nowak, M.A., 1994. Habitat destruction and the extinction debt. Nature 371, 65-66.

Vetter, D., Hansbauer, M.M., Végvári, Z., Storch, I., 2011. Predictors of forest fragmentation sensitivity in Neotropical vertebrates: a quantitative review. Ecography 34, 1-8.

Weiss, J.L., Overpeck, J.T., 2005. Is the Sonoran Desert losing its cool? Glob. Change Biol. 11, 2065-2077.

With, K.A., 2004. Metapopulation dynamics: perspectives from landscape ecology. In: Hanski, I., Gaggiotti, O. (Eds.), Ecology, Genetics and Evolution of Metapopulations. Elsevier Academic Press, Amsterdam, pp. 23-44.

With, K.A., King, A.W., 1999. Dispersal success on fractal landscapes: a consequence of lacunarity thresholds. Landscape Ecol. 14, 73-82. 